\title{
Videogames \\ um espaço intersticial de possibilidades \\ para a partilha do comum
}

\author{
Cremilson Oliveira Ramos (IFSC)
}

\begin{abstract}
Resumo
Dentre as tecnologias da mídia que ganham grande repercussão na contemporaneidade encontram-se os videogames. Esses são uma forma midiática ainda pouco explorada, principalmente no tocante a seus estudos enquanto manifestação cultural. Isso leva a questionar, tomando a literatura como base norteadora para esta pesquisa e elegendo os jogos Fable 2 e Alice: madness returns para serem objetos analisados como formas textualizadas, que elementos presentes nesses jogos permitem concebê-los como uma forma de narrativa? De que forma essa mídia eletrônica põe em contato sujeitos de diferentes locais, culturas, crenças e ideologias constituindo assim um território político de partilha do sensível? A partir dessas problematizações, reflete-se sobre as formas como essa mídia contribui para a formação de comunidades virtuais que se formam em torno da narrativa gâmica, favorecendo a interação homem-máquina e que demanda o compartilhamento de informações entre usuários.
\end{abstract}

Palavras-chave: Videogames. Mídia. Narrativa. Cultura.

\begin{abstract}
Video games are among the technologies of media which make a great impact on the contemporaneity. These media are still underused, particularly regarding to its studies as a cultural manifestation. This leads to question, taking the literature as a basis for guiding this research and choosing the games Fable 2 and Alice: Madness returns objects to be analyzed as forms of text, which elements present in these games allow one to conceive them as a form of narrative? How does this electronic media bring up subjects from different places, cultures, beliefs and ideologies thus constituting a political territory for sharing the sensible? From these questionings emerges a necessity for reflecting on the ways in which this media contributes to the formation of virtual communities that form around the narrative gâmica, favoring the manmachine interaction and demand information sharing between users.
\end{abstract}

Key-words: Video games. Media. Narrative. Culture. 


\section{A narrativa nos jogos eletrônicos}

Inicia-se este estudo partindo do pressuposto de que os textos não são apenas construções verbais e orais realizadas no mundo fenomênico. As ações da vida ao serem representadas por meio de outros objetos também constituem textos. Nogueira (2008, p. 14) apresenta os conceitos de ação prosaica e ação poiética. Essa se refere ao identificável no mundo do texto. Aquela representa o que acontece no mundo da vida. Partindo desse entendimento, o autor explica que "Textualizar (narrativa ou ludicamente) uma ação é subtraí-la ao seu regime comum e fazer entrar na ordem do discurso - isolá-la do mundo da vida, portanto, e conduzi-la a alguma forma de abstração", como os romances, os filmes, os desenhos animados e os videogames (jogos eletrônicos).

Assim como nas narrativas da literatura, como nas fábulas, por exemplo, os videogames têm sua própria narrativa que ora se aproxima ora se distancia da configuração das narrativas convencionais. Neles também há um enredo, o qual é desencadeado a partir de um conflito por personagens protagonistas e antagonistas, auxiliados por personagens secundárias, o que se desenvolve em um espaço e tempo. Esse pode ser cronológico, linear, ou psicológico, havendo retrocessos no pensamento ou lembrança das personagens, assim como é representado no cinema. Aquele, por meio das mais modernas tecnologias da computação gráfica, pode ser representação de mundos fantásticos ou maravilhosos, ou mesmo, recriações de cidades reais, como na série GTA, que reproduz Los Angeles, Nova Iorque, entre outras, ou mesmo florestas, desertos e diversas paisagens naturais com efeitos de realismo impressionantes.

A criação de espaços surreais também é algo que ganha muita ênfase e destaque nos jogos eletrônicos, como podemos perceber em Alice: madness returns. Nessa sequência de Alice no país das maravilhas, a criação dos cenários e os efeitos especiais são extraordinários, algo que só é representado de forma similar nas narrativas fílmicas. Nesse sentido, os jogos permitem uma melhor visualização ao jogador de como seriam os locais e as ações na história. Os vários cenários da narrativa são representados nas seis longas fases que o jogador deve vencer para chegar ao desfecho da história. Pontes feitas de cartas de baralhos e dominós, chaleiras e engrenagens flutuantes, caminhos de cogumelos coloridos gigantes, um desafio no fundo do mar e em mundo congelado no qual se podem observar seres presos no gelo ou uma viagem por um cenário que mais se assemelha ao interior de uma artéria, para encontrar a rainha de ouro, são alguns dos mundos surreais a que Alice deve sobreviver para descobrir o que está destruindo o País das Maravilhas. Há elementos na narrativa que marcam a intertextualidade, 
assim como outros que remetem a desconstrução das formas fixas e estáveis no modo de se perceber o mundo. Parafusos voadores que lembram borboletas insetos e pirilampos em forma de lâmpadas com asas são alguns dos seres reconstruídos no mundo diegético ${ }^{1}$. Os cenários fazem constantes referências a um tempo cronológico ao mostrar partes de relógios flutuantes no ar, ou relógios que funcionam como alavancas para abrir uma passagem. No entanto, trata-se de um tempo descontruído, estilhaçado, provavelmente menção à suposta sobreposição da modernidade e das tecnologias sobre a fantasia. Essas construções do espaço e das personagens em Alice: madness returns lembram muito as criaturas e lugares representados nos quadros de Salvador Dali, principalmente no que tange às cores e as distorções. Por exemplo, há pequenas vacas com asas de pássaro cujos ubres são desproporcionais ao corpo pequeno. Outros pássaros consistem apenas de um focinho de porco com asas. Há dentes de ouro - provável intertexto com a fada do dente das narrativas nórdicas - espalhados pelos cenários, os quais o jogador-personagem deve coletar para aperfeiçoar as armas quando coletados em certas quantidades. As armas são uma faca de cozinha, um guarda-chuva que funciona como escudo e um moedor de pimenta, que serve para "temperar" os inimigos.

Nesse sentido, é relevante a distinção que Nogueira faz entre as formas que o espaço pode ter.

Podemos falar de um espaço contingente e mutável - espaço da ação comum, do mundo da vida - e de um espaço necessário e estável - os espaços diegético e lúdico. No primeiro, desenrolam- se os fenômenos prosaicos. Nos segundos, representam-se os fenômenos textualizados. Daî que possamos indicar, por exemplo, a sala de cinema ou o campo de jogos como espaços prosaicos de mediação, nos quais o espectador e o jogador acedem a eventos textualizados - aqueles que sucedem no interior do jogo ou do filme (NOGUEIRA, 2008, p. 52).

Em outras palavras, no mundo fenomênico o espaço e os objetos nele presentes são passíveis de transformações, enquanto os espaços diégetico e lúdico se encontram em latência. Eles só se atualizam por meio de ações dos leitores, espectadores e jogadores. No caso do espaço no jogo eletrônico, o jogador pode transformar os cenários e objetos num dado momento da ação, porém tal interferência representa uma das múltiplas atualizações que o virtual permite. Sob esse prisma,

[...] o virtual é entendido [...] como um processo de transformação de um modo de ser num outro. Tal processo caracteriza-se por um movimento do virtual ao atual, no qual o virtual gera um problema ou cria uma problematização sobre o atual. Para tal problematização podem ser dadas
${ }^{1} \mathrm{O}$ mundo representado no interior dos acontecimentos narrados em contraposição ao mundo fenomênico. 
várias soluções e por diferentes processos de atualização. Um mesmo virtual é uma fonte indefinida de atualizações (LEVY, apud MENDES, 2002, p. 50).

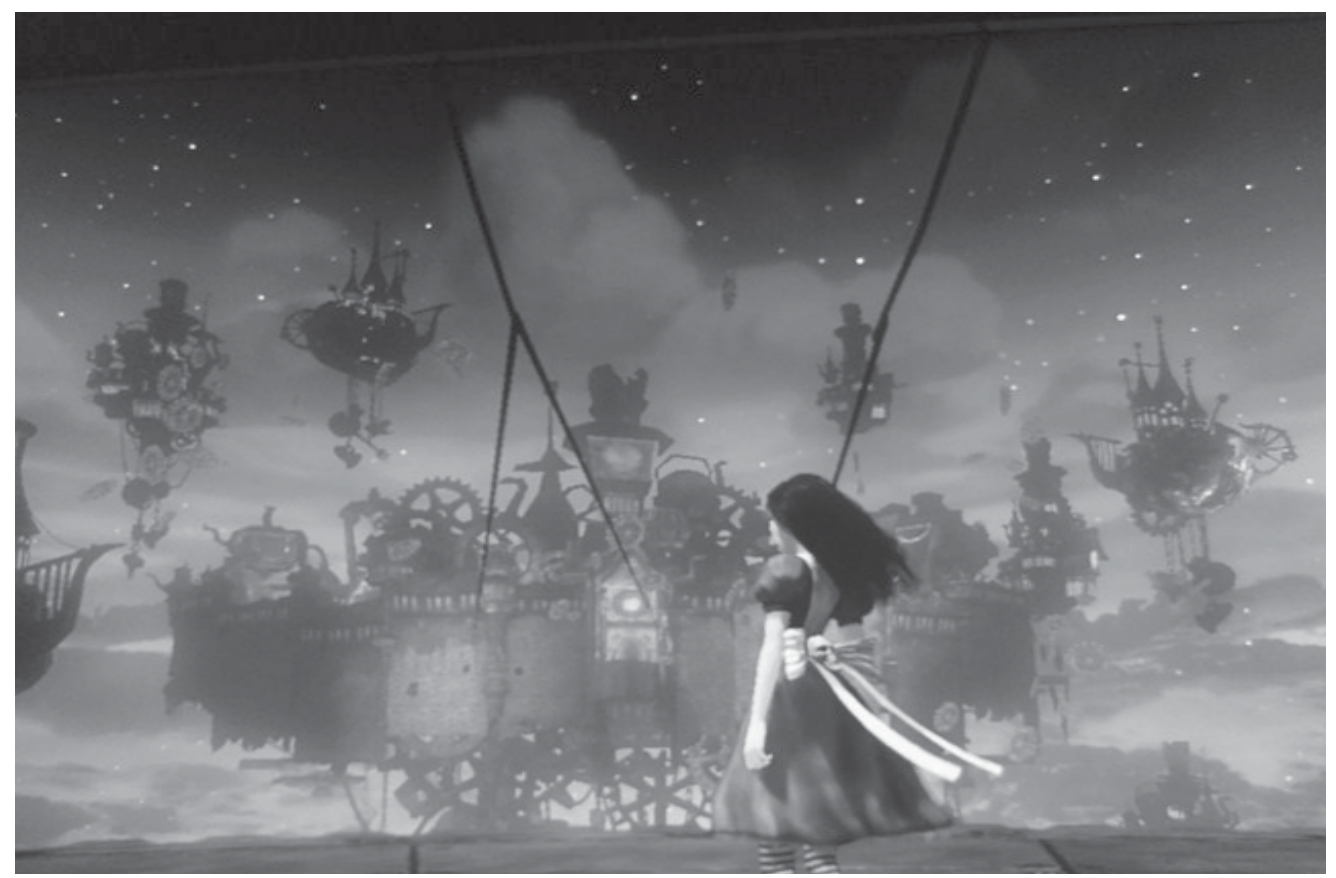

Figura 1 - Alice no mundo surreal. A desconstrução dos cenários representa a destruição de Wonderland

A temporalidade nos jogos aproxima-se das narrativas em vários aspectos. No entanto, as narrativas tendem a recuperar eventos do passado enquanto os jogos encerram em sua configuração ações que, por parte do jogador, determinam o futuro.

Identificamos [...] três modos de entender a acção em função da temporalidade: o passado, cuja categoria epistémica seria a retrospecção - numa metáfora espacial equivalente, poderíamos dizer que se trata de olhar para trás, para o consumado ou o reificado -, ao qual a narrativa estaria em melhores condições de responder; o futuro, cuja categoria epistémica seria a prospecção - espacialmente, tratar-se-ia de um olhar para a frente, para o eventual ou o idealizado -, e que o jogo estaria em melhores condições de atender; o presente, cuja categoria seria a perspectivação - espacialmente, um olhar através de uma moldura - seria o modo que melhor serviria à acção prosaica, isto é, à percepção do fluxo dos fenómenos (NOGUEIRA, 2008, p.23).

Sob esse prisma de temporalidade, percebe-se que em Alice: madness returns as ações e suas consequências impulsionam o jogador para um desfecho por meio das partes do quebra-cabeça que vão surgindo ao término de cada fase, das novidades, das aparências súbitas que causam curiosidade e estranhamento. Durante o desenvolvimento do enredo há várias digressões no pensamento de Alice. Ela alterna entre o mundo real e a fantasia, entre o pre- 
sente no qual é atormentada pela morte de sua família em um incêndio e pequenas lembranças que a levam de volta ao exato momento do acidente no passado. Nesse sentido, enquanto na literatura a narrativa visa à retrospecção - a contação de fatos do passado - o tempo nas narrativas gâmicas visa à prospecção, a um futuro que só pode ser alcançado por meio das ações do jogador.

\section{Caracterização das personagens}

Assumir o papel da personagem, desempenhar ações, participar do desenvolvimento do enredo coloca o jogador em várias posições concomitantes: de jogador, de personagem e, mesmo de narrador da história. No caso, da comunhão entre personagem controlada e jogador surge o avatar, ou seja, ao controlar a personagem de Alice, é como se o jogador assumisse seu papel, colocasse sua máscara. Personagem e jogador e as noções de tempo e espaço entram em suspensão no momento do jogo e há um desligamento desses com o mundo real. Nesse sentido, a narrativa gâmica se distingue da narrativa literária porque nessa os eventos são relatados, enquanto naquela os eventos são desempenhados pelo avatar. Daí chamar-se o jogador, nesta análise, de jogador-personagem-narrador. Nogueira afirma que para entendermos a caracterização das personagens por meio da análise da ação é importante distinguirmos as várias posições de ação a partir do princípio da imputabilidade².

O agente deve servir, portanto, como categoria epistémica para o estudo das figuras do autor, do jogador, do espectador, do actor, do narrador, do narratário, da personagem e do avatar, mas em regimes de imputabilidade diferenciados. Quer isto dizer que os domínios e dimensões críticas da acção prosaica, apesar de poderem ser espelhados nos textos, ganham, através da intencionalidade e da responsabilidade, incidências distintas - daí que um jogador possa ser castigado e um avatar não, que um avatar possa morrer mas um jogador não, que um actor possa ser criminalizado mas um personagem não, etc. (NOGUEIRA, 2008, p. 48).

Nesse sentido, a participação do jogador muda o decurso dos acontecimentos e este acaba por funcionar como narrador e contribuir para o enredo com o próprio jogo. É importante destacar que o nível de interferência que o jogador terá no enredo é algo pré-determinado pelo autor. Existiria no jogador [...] um movimento permanente de deslocação entre papéis - de narrador, na medida em que suas próprias opções condicionam, em parte, a forma como a informação lhe é apresentada, e de
${ }^{2}$ Princípio que une os conceitos de intencionalidade e responsabilidade entendidos respectivamente como a faculdade de um agente responder pelos seus atos e intencionalidade como a faculdade de um agente escolher as suas ações. 
narratário, na medida em que desvenda a informação em função do modo como esta lhe é apresentada (NOGUEIRA, 2008, p. 100). Segundo esse mesmo autor, "todo o jogador constrói o jogo como uma narrativa e [...] todo o espectador experimenta a narrativa como um jogo [...]."

Espaço, tempo e ação se imbricam nas diversas formas de narrativa. A partir da ação desempenhada pelas personagens podem-se determinar algumas diferenças entre a personagem da narrativa verbal e a da narrativa gâmica. Para tanto, analisar-se-á a personagem principal de Fable 2: Sparrow. Num mundo medieval, em que o fantástico e o maravilhoso se encontram, o jogador assume o papel de Sparrow, uma criança órfã que vive com a irmã Rose nas ruas de Albion. Para "sobreviver" o/a jovem tem de realizar muitas tarefas desafiadoras em busca de dinheiro e alimento e, para isso, as escolhes e caminhos a serem tomados influenciarão o desenvolvimento físico da personagem - inclusive de sua "personalidade" - do enredo e do desfecho da trama. Em suma, o jogador poderá escolher entre ser bom ou mal.

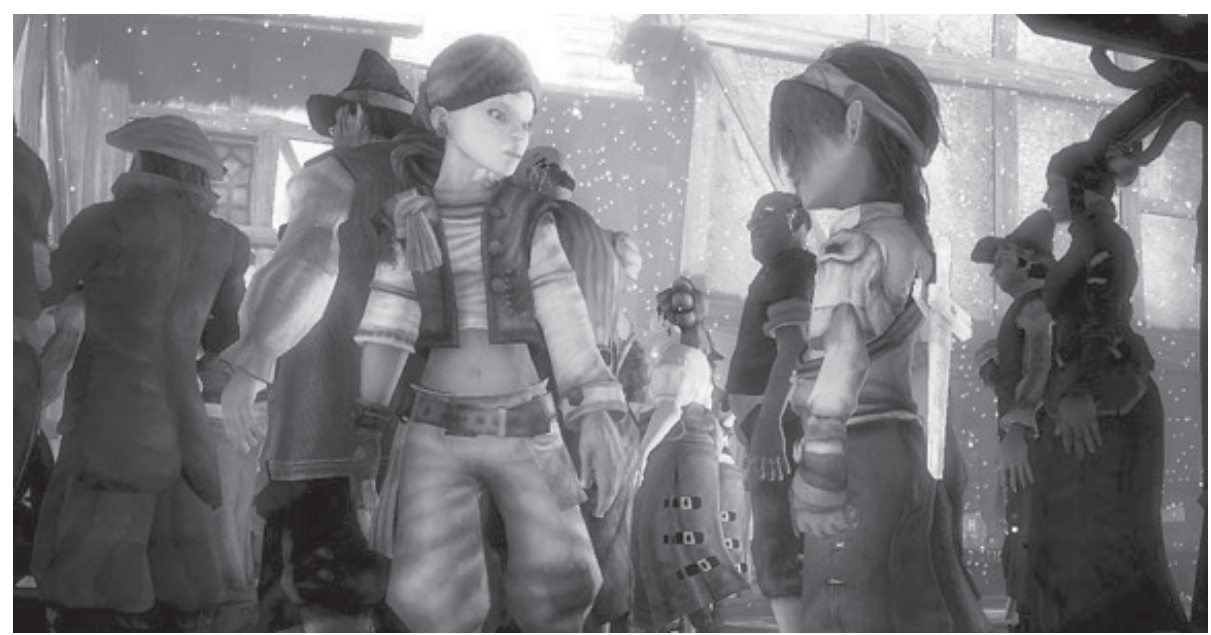

Figura 2: Os órfãos Rose e Sparrow (à direita) sobrevivendo nas ruas de Albion

As escolhas dos alimentos modificarão o corpo da personagem deixando-a esbelta ou obesa. As atitudes perante os cidadãos de Albion, como um simples gesto de pedir desculpas ao esbarrar em um transeunte, ajudarão na construção da boa índole ou não que será difundida entre todos os habitantes do mundo diegético. Se as pessoas têm boas informações sobre as ações de Sparrow, essas contribuirão para a construção de uma personagem com caráter bom e, consequentemente alterações na fisionomia da personagem vão surgindo. Do contrário, se o jogador personagem decide realizar ações de caráter negativo, como pequenos furtos em vez de trabalhar, recusar-se aos pedidos das pessoas para realizar tarefas ou cometer graves crimes como assassinato, o corpo de Sparrow passará por mudanças ao longo da trama que o identificaram com o mal. Entretanto, ações boas, como aceitar ser torturado por se recusar a castigar prisioneiros, também terão consequências negativas sobre a es- 
tética do corpo da personagem e sobre o desfecho da história. Essas modificações são melhores observadas pelo jogador-personagem no desfecho da trama. "Da mesma forma que serve para apreciar o grau ou o género de transformação ocorrida num evento, o desfecho serve também para avaliar o grau ou o género da transformação sofrida pelo sujeito (NOGUEIRA, p. 40)." O autor ainda afirma que "Mudanças no perfil (o ser) podem ser consequência de alterações no evento (o fazer); e mudanças no evento podem ser consequência de alterações no perfil. Se muda a maneira de agir, muda a maneira de ser (idem)."

Por outro lado, em Alice: madness returns as ações desempenhadas pela personagem nas situações de conflito, em que há uma dose exagerada de violência, não permitem ao observador percebê-la como uma vilã, pois as ações destrutivas de Alice são praticadas contra monstros surreais que se distanciam da forma humana. Não há prejuízo ao ser humano. Para chegar ao desfecho e acabar com sua suposta insanidade e descobrir o que está destruindo O País das Maravilhas, os atos maus justificam um final bom. As dimensões críticas da ação são representadas sempre por dois polos. Segundo Nogueira (2008, p. 28), os conceitos de bom e mau, belo ou feio "permitem avaliar a qualidade da acção reduzindo o seu julgamento à correspondência, ou não, entre o propósito que a orienta e as consequências que provoca". O autor ainda menciona que

Os conceitos de belo e de feio [...] servem para qualificar o modo como a acção e conduzida, isto é, averiguam a correspondência entre decisão e execução. A sua avaliação pode ser exterior à axiologia - por isso podemos afirmar que é possível praticar o mal de uma forma bela e o bem de uma forma feia - quer à teleologia - uma acção bela não é necessariamente boa, ou seja, bem sucedida (NOGUEIRA, 2008, p. 29).

Essas reflexões permitem afirmar que o modo com que a narrativa gâmica desenvolve suas personagens difere da forma estática como elas aparecem na literatura, ou da narrativa fílmica, na qual há dinamismo nas personagens, porém, com uma forma única de atualização. Essas têm sua constituição dada a priori enquanto na virtualização dos jogos eletrônicos as características das personagens estão em latência, dependendo do jogador para serem construídas, embora a ação, ainda assim, seja determinante para a caracterização da personagem.

Entre a frase e o texto, entre o plano e o filme, entre o lance e o jogo, aquilo que encontramos são escalas de crescente complexidade na articulação de unidades de acção simples em totalidades abrangentes. [...] Entendemos assim a acção 
como sistema e tal reflete-se na organização funcional e morfológica que o texto assume quando a descreve, na narrativa, ou quando a prescreve, no jogo (NOGUEIRA, 2008, p. 27).

Vale lembrar que o maior dinamismo do jogo em relação ao relato acontece porque se trata de uma mídia que representa a realidade por meio da simulação. O jogador tem certo poder sobre as causas e efeitos que interferirão nas direções que o enredo pode tomar. Porém, isso só acontece de acordo com o que o autor do jogo permite previamente. Nesse sentido, Nogueira (2008, p. 216), afirma que "[...] à medida que nos afastamos da narrativa e nos aproximamos do jogo -, a soberania do autor vai diminuindo e uma partilha de autoridade sobre o texto vai-se acentuando." Por isso consideramos que em um jogo eletrônico o jogador, ao contribuir para o desenvolvimento do enredo, também assume a autoria do texto lúdico.

\section{Como os jogos eletrônicos constituem um lugar de contato?}

É importante perceber os videogames não apenas modos de lazer, mas como construtos culturais que encerram em sua constituição processos complexos de significação. Nesse sentido, Bogost (2008, p. 119) entende os videogames "não apenas palcos que facilitam práticas culturais, sociais ou políticas; eles são também meios em que os próprios valores culturais podem ser representados - para crítica, sátira, educação ou comentário." Ele ainda afirma que, “[...] podemos aprender a ler os jogos como expressões deliberadas de perspectivas particulares. Em outras palavras, [eles] fazem alegações sobre o mundo, que os jogadores podem entender, avaliar e deliberar."

Sob essa perspectiva, concebem-se os videogames como lugar possível de partilha do comum, a partilha do sensível que Rancière atribui as artes por serem políticas. Segundo o autor, a arte é política

[...] antes de mais nada pela maneira como configura um sensorium espaço-temporal que determina maneiras do estar junto ou separado, fora ou dentro, face a ou no meio de...Ela é política enquanto recorta um determinado espaço ou um determinado tempo, enquanto os objetos com os quais ela povoa este espaço ou o ritmo que ela confere a esse tempo determinam uma forma de experiência específica, em conformidade ou em ruptura com outras: uma forma específica de visibilidade, uma modificação das 
relações entre formas sensíveis e regimes de significação, velocidades específicas, mas também e antes de mais nada formas de reunião ou de solidão (RANCIÈRE, 2005, p. 2).

Tais formas de reunião podem ser observadas nas comunidades de jogos virtuais, as quais possibilitam o contato, antes dificultado pela distância geográfica, entre indivíduos e grupos das mais remotas partes do globo. Não se pode negar a existência também de solidão nesse tipo de interação, a qual tem como linguagem mediadora a interface comunicacional gráfica do computador, que se pode entender como uma prótese de extensão dos corpos que permite a entrada e intervenção no mundo diegético. No entanto, trata-se de uma solidão física, a qual é preenchida pela presença virtual de outros interlocutores que também fazem uso de tal prótese. A solidão é partilhada e na solidão há a partilha numa espécie de relação antitética: a solidão que reúne e que põe em contato. Dessa forma, os jogos eletrônicos, enquanto manifestação artístico-cultural, têm imbricada tal partilha nas múltiplas simulações (representações?) que fazem do mundo da vida.
A partilha do sensível faz ver, concomitantemente, a exis- tência de um plano comum sensível e espaço-temporal dos corpos, das práticas, dos discursos e dos processos de sub- jetivação, e a segmentação desse comum em partes defini- das, seu recorte em tempos e ocupações específicas, suas relações de inclusão e exclusão, de interioridade e exterio- ridade, os regimes que organizam modos de ver e de dizer e que deixam folgas nas quais a negociação de sentidos é possível (ROCHA; KASTRUP).

As narrativas dos jogos eletrônicos, especialmente as do tipo RPG, colocam no campo de ação personagens que representam as mais variadas culturas e lugares. O interesse por esse tipo de gênero é porque sua dinâmica importa na "construção de uma narrativa a partir da "inserção" do jogador na trama que vai se desvelando, formando a linha narrativa (ARANHA, 2004, p. 50-51), e poder-se verificar o modo de participação nos jogos eletrônicos, a experiência mediada pela linguagem que articula imagens e sons através da participação ativa do usuário.

Podem-se tomar como exemplo os jogos de guerra que têm como foco a conquista e o desenvolvimento de civilizações. Nesse tipo de jogo, há predomínio da dominação do mais fraco contra o mais forte, do civilizado e do não civilizado, da opressão do desenvolvido tecnologicamente sobre aquele que ainda vive em estágios sociais arcaicos ou primitivos. As relações antagônicas nos encontros de culturas nos jogos é uma representação que encerra em sua configuração os padrões 
de domínio presentes no colonialismo e no eurocentrismo. Sob esse prisma, Bhabha nos diz que:

A construção do sujeito colonial no discurso, e o exercício do poder colonial através do discurso, exige uma das formas da diferença - raciais e sexuais. Essa torna-se crucial se considerarmos que o corpo está sempre simultaneamente (mesmo que de modo conflituoso) inscrito tanto na economia do prazer e do desejo como na economia do discurso, da dominação e do poder (BHABHA, 2003, p. 107).

Percebe-se, então, que a representação da história não mais se faz apenas por meio da literatura escrita ou oral, novela, cinema ou teatro, mas ganha espaço nos jogos eletrônicos com o diferencial de que neste suporte discursivo o jogador-personagem-narrador interage com o enredo escolhendo caminhos e posições, interferindo na ação e mesmo no desfecho. Eles envolvem o jogador na dimensão do prazer, os fazem refletir na dimensão do discurso e permitem assumir papéis que negociam com o poder. A possibilidade de assumir a posição de um grupo indígena, por exemplo, permite ao jogador observar a história pelo ponto de vista do colonizado, o que amplia a dimensão do conhecimento dos "fatos" históricos ou, no mínimo, incita-os a uma leitura questionadora do mundo ao apresentar novas possibilidades além daquelas impostas pela história. Temos aqui, então, uma possibilidade de ver ética e esteticamente a interioridade a partir da exterioridade. É relevante salientar que os jogos eletrônicos se inscrevem na economia do prazer e do poder porque com seus recursos tecnológicos estimulam sensorialmente os jogadores gerando prazer nos mesmos, e se inscrevem no discurso do poder, pois de acordo com Mendes,

[...] quando as técnicas de dominação são empregadas por sujeitos sobre outros sujeitos, os sujeitos que sofrem a ação - por intermédio das técnicas de si - participam ativamente tanto dos seus autogovernos quanto do governo dos outros sobre si mesmos, ao entender que a ação de outros é benéfica para si. De outro lado, por tentarem se autogovernarem, os sujeitos resistem às técnicas de dominação, mesmo que assumindo para eles algumas estratégias das técnicas de dominação como formas de resistência (MENDES, 2002, p. 49).

Bogost (2008, p. 128), ao analisar o que ele chama de retórica procedimental presente nos jogos eletrônicos, mostra-nos que os videogames contêm em suas temáticas elementos representacionais dos sistemas que compõe o mundo real, afirmando que "[...] Um uso da retórica procedimental é expor e explicar os modos ocultos de pensamento que frequentemente dirigem o comportamento social, politico ou cultural." Para exemplifi- 
car, o autor menciona alguns jogos, como Animal Crossing, em que os jogadores são instigados a refletir sobre ganhos e perdas com a aquisição de imóveis, lucros no trabalho e acúmulo de bens. Em McDonald's Videogame, segundo o autor, os jogadores são colocados no controle da empresa multinacional e têm de enfrentar situações como a exploração do meio ambiente em países do terceiro mundo e de mão-de-obra barata para a criação de gado, o uso de hormônios para acelerar o crescimento dos bovinos (o que pode acarretar doenças nos consumidores), pagamento de propinas a políticos, entre outras situações que levam o jogador a refletir sobre questões éticas e morais. Outro jogo analisado por Bogost é Bully, o qual retrata as perseguições sofridas por alunos menores dentro das escolas de ensino médio. Apesar das críticas ao jogo, ele representa a realidade e nos permite refletir sobre como os conflitos são negociados entre os jovens na escola e sobre como as políticas educacionais atuam no sentido de interferir nesse problema. De acordo com Bogost (2008, p. 136), “jogar videogames é um tipo de alfabetização. Não a alfabetização que nos ajuda a ler livros ou escrever trabalhos de curso, mas o tipo [...] que nos ajuda a construir ou a criticar o sistema em que vivemos." O autor ainda sustenta que,

Como todos os artefatos culturais, nenhum videogame é produzido em um vácuo cultural. Todos carregam as tendências de seus criadores. Videogames podem ajudar a lançar luz sobre as tendências ideológicas. Às vezes essas tendências não são intencionais e estão profundamente ocultas. Outras vezes, os próprios artefatos querem expor as tendências de seus criadores como positivas, mas o que, é claro, pode então ser lido como apoio ou oposição (BOGOST, p. 128).

A necessidade que o jogador tem de conhecer o desfecho do jogo faz com que esse entre em contato com outros jogadores para compartilharem informações acerca do progresso nas partidas, fases ou níveis. Dessa necessidade surgem diversas comunidades de jogos divididas em faixas etárias e gêneros de jogos. Essas comunidades compartilham textos informativos por meio de mídias como revistas especializadas em games, programas de TV e suportes virtuais como fóruns, blogs e outras redes sociais, permitindo assim a difusão da ideia de trabalho colaborativo. Como explica Squire (2007, p. 9), "no [jogo] Avatar, por exemplo, a dificuldade e as variáveis do jogo são manipuladas de forma que os jogadores são forçados a colaborar com outros jogadores e criar os laços que podem sustentar uma comunidade de jogo online." Ele ainda afirma que com o desenvolvimento de RPGs online gráficos como Everquest, que tem milhares de jogadores online em momentos dados, e a próxima geração de 
sistemas de consoles vindo equipadas com modems, jogar online parece ser uma parte importante do meio ambiente do jogo. Dessa forma, percebe-se que o avanço nas tecnologias de comunicação virtual permite o crescimento acentuado dessas comunidades e a possibilidade de aproximação entre diversas comunidades de jogo em nível global, como se pode observar na explicação de Pearce:

Com a emergência das redes digitais, variedades totalmente novas de comunidades de jogos adultos começaram a aparecer, o que foi possibilitado pelos computadores pessoais e redes globais difundidos, cujo avanço gráfico e capacidade de transmissão estavam antes confinados em laboratórios de pesquisa universitários. Algumas dessas são extensões de formas não digitais de jogo, enquanto outras oferecem experiências e cenários completamente novos. As redes amplificam escala, progressão e alcance geográfico das comunidades de jogo, permitindo a elas cresceram em tamanho, mais rápido do que seus homólogos off-line. Esses fenômenos dão abertura para novos playgrounds criativos, não apenas dentro dos discretos espaços de jogo em rede, mas também através de intervenções no mundo real, como "realidade alternada" e "jogos amplos", ao quais acontecem por meio de mídias múltiplas e no mundo físico; "mobs inteligentes”, interações entre grandes grupos possibilitadas por tecnologias móveis; e outras formas emergentes de jogo que borram as fronteiras entre o real e o virtual, vida cotidiana e imaginação, trabalho e brincadeira (PEARCE, 2009, p. 5-6).

Como sugere a autora, o contato virtual entre diferentes grupos por meio da Internet permite um estranhamento frente à ideia de originalidade, estabilidade, fixidez a partir do momento em que os jogadores se veem frente a possibilidades alternativas. Nos jogos de esporte, como o futebol, por exemplo, existe o encontro de diversas nacionalidades e diferentes etnias são representadas e colocadas juntas nos gramados para interagir. Considerando o alcance global dos videogames e indistinção de classe social ou poder aquisitivo dos jogadores que eles atingem, eles levam a comunidades mais fechadas, ou extremistas, em suas próprias culturas o esporte que é conhecido mundialmente. Dessa forma, o jogo adentra a cultura do outro e insere nela elementos que antes não eram pensadas ou concebidas. O que se pretende dizer é que, por exemplo, em um país predominantemente branco como a Áustria, em que políticos já fizeram menção em proibir a entrada de negros, ou nas manifestações de preconceito raciais violentas nos Estados Unidos, ou mesmo na África do Sul, por mais resistência que grupos extremistas possam demonstrar ou por mais que a política desses países compactue com a discriminação, ainda assim, indivíduos que tenham contato com o jogo observarão 
personagens negros, como Ronaldinho Gaúcho, interagindo com ingleses, alemães, muçulmanos. Nessa zona intersticial promovida pelo videogame, mesmo que o jogador se posicione contrariamente à hibridização, o simples fato de jogar o coloca em uma posição de reflexão que apresenta um novo modo de ser-estar no mundo.

Ainda que apenas através da tela da TV ou do computador, mesmo que seja só por meio da virtualidade, as formas como o personagem-jogador vai atualizar essas informações não serão as mesmas como faria antes dessa exposição. Seu olhar já estará contaminado pela possibilidade de estar com o outro, um outro que não tem a mesma cor de pele que a dele, que fala uma língua estranha, ainda que essa não tenha sido a intenção do criador/ autor do jogo. De acordo com Bogost,

\begin{abstract}
A subjetividade inerente dos videogames cria espaços de dissonância entre o modelo procedimental de um sistema fonte do designer e a subjetividade do jogador, preconcepções, e entendimento da simulação. Isso é onde os videogames se tornam expressivos: eles incitam os jogadores a interrogar e conciliar seus próprios modelos de mundo com os modelos apresentados no jogo. [...] Nós também podemos usar este equipamento para convidar o jogador a ver o mundo em novos e diferentes modos, [...] a fazer argumentos sobre o modo como o mundo funciona (BOGOST, p. 2-3).
\end{abstract}

Por muito tempo os jogos foram criados dentro de uma perspectiva heteronormativa, deixando à margem as temáticas do gênero e da sexualidade. Atualmente os criadores de jogos vêm dando uma ênfase considerável a esses assuntos e inserindo nas narrativas a presença de sexualidades múltiplas e invertendo o papel da personagem principal da história que sempre era exercido por um homem, colocando no papel central a figura feminina.

O exercício das relações de poder se dá por marcas que moldariam uma personagem irresistível aos interesses masculinos e heterossexuais. Com isso, por um lado, o exercício de poder se daria pelos jogadores que vão controlá-la. Por outro lado e ao mesmo tempo, o exercício das relações de poder se baseia em marcas heterossexuais consagradas culturalmente para capturar o "sexo oposto". Parece-me que essas marcas dão base para modos de endereçamento orientados a sujeitos-jogadores identificáveis com uma cultura masculina e heterossexual.

Quando, porém, o jogador de gênero masculino transforma-se na personagem, em sentido muito específico, ele estaria assumindo outro gênero que não o seu (MENDES, 2004, p. 202). 
Pode-se perceber que os jogos procuram se aproximar ao máximo da representação da realidade e, dessa forma, prender a atenção dos jogadores e, assim, lançam mão de temas, por muitos, considerados polêmicos. $\mathrm{O}$ jogador pode ir além de assumir o gênero oposto ao seu, como também desenvolver sua performance sob outra orientação sexual. Quanto à questão do papel desempenhado pelas mulheres nos jogos, verifica-se que:

Não foram poucas as mulheres na vida do Comandante Shepard, herói da série "Mass Effect": Ashley, Miranda e até a alienígena Tali tiveram suas passagens românticas nos 2 primeiros jogos. Em "Mass Effect 3", porém, o herói vai ampliar as suas possibilidades de relacionamento, com a inclusão de homossexualismo masculino no game. Mesmo em sua versão masculina, Shepard pode flertar e se envolver com outros homens em [...] incluindo relações sexuais e cenas picantes. Nos jogos anteriores [...] apenas a versão feminina do protagonista podia se relacionar com personagens de ambos os sexos (UOL jogos, 2012).

Nesse sentido, percebe-se os jogos como um território político de partilha do sensível, um espaço de possibilidades, dado que todos os jogadores, independente de sua orientação sexual, estão interagindo com personagens que podem ser heterossexuais, homossexuais, transgêneros, entre outros, pois para a consecução da narrativa as ações determinam a inter-relação, ajudando a (des)construir saberes hegemônicos de dominação. Um jogo que põe em pauta essa temática é o The Sims, ao apresentar personagens de diferentes raças, gêneros e idades. $O$ jogador pode inclusive escolher as características fenotípicas de sua personagem. Fazendo uma leitura sobre simulação, narrativa e retórica nos jogos eletrônicos, Frasca menciona que:

[...] o modo como os designers de The Sims negociaram com casais gays não foi apenas por meio de representação (por exemplo, ao permitir aos jogadores colocarem faixas nos seus jardins), mas eles também decidiram criar uma regra para isso. Nesse jogo, relacionamentos do mesmo gênero são possíveis. Em outras palavras, a homossexualidade é realmente uma opção para os jogadores e está incluída no modelo de simulação. No entanto, nós poderíamos perfeitamente imaginar um jogo conservador em que os designers tivessem excluído os relacionamentos de mesmo gênero. A homossexualidade não é o objetivo de The Sims, apenas uma possibilidade (FRASCA, 2003, p. 9).

Além disso, a inclusão desses temas permite a ampla discussão entre os jogadores, o que pode ser percebido nas redes sociais da Internet como fóruns de discussão, blogs e sites especializados em divulgação de notícias sobre jogos. Assim como na vida fenomênica, as relações homoafetivas passam a servir 
de base para a construção das histórias virtuais, como se percebe em entrevista com o diretor de desenvolvimento de jogos Peter Molyneux publicada em um fórum do UOL jogos.

O casamento homossexual é uma realidade e também o vai ser em Fable III. Em entrevista com o VG247, Peter Molyneux disse que o casamento entre pessoas do mesmo sexo é possível e que até podem adotar crianças. Quando feita a pergunta se podíamos ser homossexuais no jogo, Molyneux respondeu: "Absolutamente. Você pode ter um casamento do mesmo sexo. E pode adotar também. E existem doenças sociais. Passar isso através da Microsoft GeoPoli é difícil, posso garantir.” (UOL jogos, 2012).

Como se percebe na fala do diretor, há políticas nas empresas criadoras de jogos que barram a publicação de certos temas. No jogo em questão, entre as dicas sobre relacionamentos que se encontram no manual, descobre-se que se pode inclusive pagar por sexo com prostitutas e/ou michês, os quais vivem nas partes mais miseráveis da cidade. "Seja você casado ou não, é possível fazer sexo com muitas das pessoas com quem você encontra durante as suas viagens, seja por amor ou por dinheiro (Manual Fable III, p. 22).” Longe de fazer apologia à prostituição, considera-se que, por meio dos jogos, as ações que provocam estranhamento são colocadas à luz dos acontecimentos rotineiros, e essas deixam de ser excêntricas. Corroborando essa afirmação, Bogost (2008, p. 122) sustenta que há “jogos [que] vão além de modelos de mundos fantásticos, criando representações do mundo cotidiano que podem dar aos jogadores novas perspectivas do mundo que eles habitam." Percebe-se que há um crescente interesse dos designers de jogo em explorar as minorias usando-as como pano de fundo, ou sub-repticiamente, para suas criações. Isso pode ser apenas uma estratégia de marketing para acentuar as vendas de jogos eletrônicos ou mesmo o surgimento de uma mudança de paradigma que demostra o real comprometimento desses profissionais com a divulgação de causas sociais. Independentemente das causas, o que importa é que os efeitos refletem que os jogos eletrônicos estão deixando de ser vistos como apenas uma forma de entretenimento, pois seu conteúdo põe em crise - ao menos desestabiliza - modos canônicos de se ler o mundo.

Pelo exposto, entende-se que os jogos eletrônicos apresentam-se como textualizações de dos acontecimentos cotidianos, permitindo em suas narrativas que o jogador-personagem-narrador transite pela história, interferindo no enredo e se modificando pelo contato nesse espaço de possibilidades. Sendo textos, utilizam-se de várias formas de linguagem nas quais a mediação entre o jogador e a narrativa pode acontecer por meio da interface gráfica, bem como pela linguagem verbal e não verbal. 
Ao se por em contato, grupos de diversas partes do globo compartilham informações e modos de fazer a partir da necessidade que têm de atingir o desfecho dos jogos. Parafraseando Bhabha (2003), os jogos, dessa forma, constituem-se entrelugares que "fornecem [...] terreno para estratégias de subjetivação - singular ou coletiva - que dão início a novos signos de identidade e postos inovadores de colaboração e contestação, no ato de definir a própria ideia de sociedade." A narrativa do mundo diégetico do jogo permite ultrapassar as narrativas originárias e iniciais.

\section{Referências}

BHABHA, Homi. O local da cultura. Belo Horizonte: UFMG, 2003.

BOGOST, Ian. Persuasive games on mobile devices. Cambridge, MA: the MIT Press, 2007.

The Rhetoric of Video Games. The Ecology of Games: Connecting Youth, Games, and Learning. Cambridge, MA: The MIT Press, 2008.

ELECTRONIC ARTS. Alice: madness returns. Manaus: Videolar, 2011.

FRASCA, Gonzalo. Simulation versus narrative: introduction to ludology. Routledge, 2003.

LIONHEAD STUDIOS. Fable 2. Redmond: Microsoft Game Studios, 2009.

Fable 3. Redmond: Microsoft Game Studios, 2010.

MENDES, Cláudio Lúcio. Controla-me que te governo: os jogos para computador como formas de subjetivação e administração do “eu”. 2004. Tese (Doutorado em Educação) - Programa de Pós-graduação em Educação, UFRGS.

NOGUEIRA, Luís. Narrativas fílmicas e videojogos. Portugal, Covilhã: LabCom, 2008.

PEARCE, Celia. Communities of play: emergent cultures in multiplayer games and virtual worlds. Cambridge, MA: the MIT Press, 2009.

RANCIÈRE, Jaques. Politica da arte. 2005. Trad. Mônica Costa Netto. <http://www.sescsp.org.br/sesc/images/upload/ conferencias/206.rtf $>$. 
ROCHA, Tatiana Gomes da; KASTRUP, Virginia. Partilha do sensivel na comunidade: interseções entre psicologia e teatro. In: Estudos de Psicologia, 2008, 13(2), 97-105.

SQUIRE, Kurt. (2003). Video games in education. International Journal of Intelligent Simulations and Gaming, 2003, (2) 1, 4962. <http:/ / educationarcade.org/research>.

UOL JOGOS. Fable 3 permite casamento homossexual e adotar crianças! (+Doenças Sociais?! AIDS?!). < http:// forum.jogos. uol.com.br/fable-3-permite-casamento-homossexual-e-adotarcriancas-doencas-sociais-aids_t_908392>.

Herói tem opção de 'sair do armário' em "Mass Effect 3".

<http://jogos.uol.com.br/ultimas-noticias/2012/03/02/

heroi-tem-opcao-de-sair-do-armario-em-mass-effect-3.htm $>$. 